Jean E. Laurent and Robert M. Leicht (2017) "Cross Functional Project Teams in Construction: A Longitudinal Case Study.” In: LC3 2017 Volume II - Proceedings of the 25th Annual Conference of the International Group for Lean Construction (IGLC), Walsh, K., Sacks, R., Brilakis, I. (eds.), Heraklion, Greece. Pp. 317-324. https://doi.org/10.24928/2017/0063

\title{
CROSS-FUNCTIONAL PROJECT TEAMS IN CONSTRUCTION: A LONGITUDINAL CASE STUDY
}

\author{
Jean E. Laurent ${ }^{1}$ and Robert M. Leicht ${ }^{2}$
}

\begin{abstract}
For many years traditional project delivery methods have been utilized in the construction industry, but new delivery systems such as IPD are being developed to answer the need for more integrated approaches. Studies have been conducted to assess the impact of project delivery method on project performance, but few focus on the effect of team composition and organization. However, many factors influence the need for evolving cross-functional project teams (CFPTs) as project needs change and there are additions of new participants to the project. This research presents a case study of an IPD project delivered at the Pennsylvania State University for a mixed-use laboratory, office and classroom building. The objective is to demonstrate the composition and evolution of the CFPTs organization, from the beginning of the design through early construction. This study shows that three main causes impacted the organization of CFPTs. First, the on-boarding of new project participants necessitated new CFPT organization to better fit members into specific groups. Second, certain CFPTs were created in order to achieve a specific task, leading to the dissolution of the team once the task is achieved. Third, CFPTs can show low performance related to their original goals requiring the project team to adjust the CFPT organization. The IPD structure showed unique organizational flexibility as CFPTs, leaders and members were replaced or exchanged to better fit the project needs when new members are added to the team, or if a member was not effective in meeting changing project needs.
\end{abstract}

Keywords: Cross-Functional Project Teams, Lean, IPD, Integrated Projects.

\section{INTRODUCTION}

Typically, construction projects follow the organizational structure driven by the type of delivery method selected. Konchar and Sanvido (1998) refer to Design-Bid-Build (DBB) as the most commonly utilized delivery method, where the owner holds separate agreements with the architect and the general contractor, that is engaged at the construction stage. On the other hand, with the Construction Management at Risk (CMat-Risk) method, the owner contracts a construction manager responsible for the management and the construction of the facility earlier in design to work with the design team. More recently Ling et al. (2004) refer to Design-Build (DB) as a delivery method where the owner hires a single entity responsible for the design and the construction of the project. These three delivery methods have distinct impacts on project performance, with a significant difference in the contractors' ability to influence the design for integration with construction processes. The concept of Integrated Project Delivery (IPD)

1 Graduate Student, Department of Architectural Engineering, The Pennsylvania State University, University Park, PA, USA, jzl6016@psu.edu

2 Assistant Professor, Department of Architectural Engineering, Director of Partnership for Achieving Construction Excellence (PACE), The Pennsylvania State University, University Park, PA, USA, rmleicht@engr.psu.edu 
leverages principles from the Toyota Production System (TPS) and Lean Construction, using technologies and organizational methods to create value for the owner and improve project outcomes (Seed 2015). Contrary to other types of project delivery methods, in an IPD project the owner, the designers and the primary contractors share a single contract, enabling much earlier involvement of the key participants (El-Asmar et al. 2013). The increasing demand for IPD has led to the creation of standardized contractual documents for industry organizations, such as American Institute of Architects (AIA) and the Associated General Contractors (AGC). Thus, as industry representative and leader the AGC (2009) and the AIA (2007) published Consensus Documents 300 and the C195 standard forms of agreement. The use of IPD presents notable advantages, as Mossman (2008) notes a compact definition of IPD as a way to "collaboratively align people, systems, business processes and practices to optimize value for the client." He specifies that the benefits vary depending on the role taken by the team members, but similarities are identifiable due to the nature of IPD contracts. For clients it becomes easier to link improved value and higher quality design with business objectives. Furthermore, Thomsen (2010) refers to the early involvement of prime contract members and describes this engagement as the means to achieve defect-free buildings. Therefore, a project becomes easier to design with shorter documentation times and better-integrated design benefits all the members.

Leicht et al. (2015) relate the different delivery methods and stipulate that the method itself is not the determining factor for success. The use of highly integrated teams and development of cohesive groups were found to be the key enablers for increased project performance. Integrated projects strongly depend on team organization, more specifically on the use and management of cross-functional teams (CFT). CFTs originated from the manufacturing industry in the late 1970s to improve product development, and have been used increasingly since then. According to Krajewsky and Ritsman (2005), a CFT regroups people from within the same company, but brings together different areas such as finance, marketing, management and other departments to work toward a common objective. Henke et al. (1993) relates specific considerations concerning team structure and composition:

1. CFTs usually gather between eight to 10 members

2. Each CFT is responsible for self-management.

3. When different CFTs are established to work on the same project, they often integrate support groups to assist the main CFTs, with all groups under the control of the Product Management Team (PMT).

UHS (2014) and Cheng (2015) emphasize the need for cross-discipline collaboration via the use of CFTs that include necessary members to respond to a specific scope, such as an estimator or specialty trade contractor. Qiu et al. (2009) highlight the need for interactional fairness on the performance of CFTs, but they do not provide specific ways to achieve it. Additionally Hickethier et al. (2013) focus on the social network analysis of information between members in IPD projects and highlight the need for utilizing the CFT approach without giving specific organizational consideration.

The difference between a Cross-functional project team (CFPT) and simply a Crossfunctional team (CFT) is that in a CFPT participants are brought together to work on a single project for a limited amount of time. However, project management methods seeking the organization of cross-functional project teams (CFPTs) in construction projects are not well defined in current literature. Gaps in literature concerning CFTs organization in IPD projects lead to the following question: how do cross-functional teams 
organize and evolve in project-based organizations in the building design and construction industry?

\section{CASE STUDY}

\subsection{Background}

The Pennsylvania State University delivered its first project using an Integrated Project Delivery contract. This project was selected to allow easier communication and collaboration with the project team. The project consisted of the demolition and reconstruction of the Agricultural and Biological Engineering (ABE) building of about $77,000 \mathrm{ft}^{2}\left(7,000 \mathrm{~m}^{2}\right)$ of new construction, and, a $16,000 \mathrm{f}^{2}\left(1,500 \mathrm{~m}^{2}\right)$ renovation of the existing structure. The project incorporated new graduate education labs, research labs, offices, classrooms, a fermentation facility, and a maintenance shop. The team pursued LEED certification for a total estimated construction cost of $\$ 30$ million ( $€ 27$ million), with a construction start in early September 2016 and completion in winter 2017. The IPD contract gathered five signatory partners: owner, designer (architect and engineer), general contractor, mechanical contractor and electrical contractor. Penn State first selected the designer and general contractor as a team, followed by the selection of specialty contractors. Finalizing the original selection process, the IPD team presented a list of five goals that they wish to achieve:

1. Enhance student and faculty experience (support excellence in research and teaching),

2. Respect, reinforce and improve PSU-ABE brand and image,

3. Building design quality (design and materials should set a high standard for architectural aesthetics and quality),

4. Improve building neighborhood (building should communicate with the neighboring project and landscape), and,

5. Life cycle and sustainability (the project should minimize life costs, and remain relevant for a 50 to 100 years lifecycle).

In order to regroup members from different companies on specific project scopes and objectives, the participants self-organized by cross-functional project teams. The Project Management Team (PMT), gathering members of all five signatory firms, is responsible for decision-making in instances when the CFPTs cannot come to a common agreement. The other members are divided into several scope-specific CFPTs, focusing on achieving project goals in conjunction with the Target Value Design process (TVD). TVD is a management technique that has been utilized in the manufacturing industry to achieve cost predictability during new product development (Zimina et al. 2012). According to Pishdad-Bozorgi et al. (2013) designers need the assistance of builders to determine design alternatives, estimate costs, and provide value engineering services during the design phase. Therefore, TVD involves both current and continuous processes of designing to set a target value and assessing the team performance toward achieving the design targets. This method creates possibilities for the project team to achieve the greatest value for the owner. Furthermore, during design, other members were selected and added to the team, as needed, to bring expertise by system. The non-signatory design-assist partners have different contracts payment terms, depending on their degree of influence on the project. Some of the design-assist contracts are incentivized through shared savings, while others are under traditional lump sum terms. Figure 1 shows an example of the contractual 
relationships among project participants. The signatory members are linked to the IPD contract; each of the signatory members has subcontractors, some of which are incentivized while others are not.

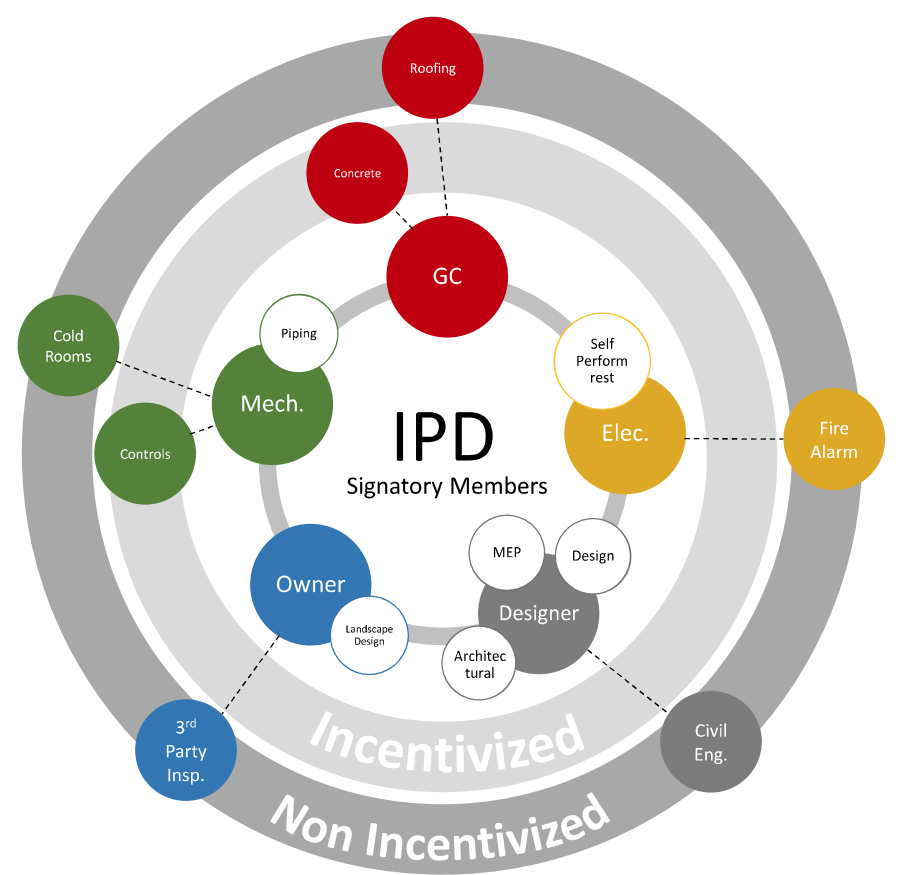

Figure 1: Project team contractual relationships - Example

\subsection{Methodology}

To develop this case study across the entire design phase, the project was tracked from the beginning of the design process to the early stages of construction. The project team held general meetings once a month at the university, allowing mapping of the evolution of the team organization throughout the project. Through working sessions with the general contractor's project manager a draft of the overall CFPT evolution was created. Furthermore, in order to develop an accurate CFPTs map evolution; interviews with a project manager from the five signatory members were held. The five interviews focused on validating the CFPTs evolution, including all organizational modifications, additions, or removals of members. This approach allowed the case study to reflect a broad, longitudinal picture of the evolution of the CFPT throughout the design phase, as well as making sure that all elements accurately reflect reality. Eventually, the information obtained during the interviews completed the original CFPT map evolution to provide a final version; presented in Figure 2, that was validated by the project team members in a follow-up meeting. 


\section{Cross-Functional Project Team Composition AND EVOLUTION}

Figure 2 represents the evolution of the three CFPTs throughout the design phase of the project. The first CFPT relates to the Program Validation, required to be completed in order to enable other CFPTs to begin working. Once this task was complete, the project team created a set of CFPTs using personnel from the first two members (designer and general contractor) of the team that were selected in January 2015. The CFPTs were created to focus on the main building systems of the project, such as: Environmental system (MEP), Shell and Envelope, Site and Fit-out. Participants of each CFPT were chosen based on their capabilities to help the CFPT reach its goals and objectives. A leader was chosen, by common agreement, among CFPT participants to govern each. Then, each CFPT evolved differently based on various elements impacting the need for group and member modifications. Hence, Figure 2 shows the three main organizational changes experienced by the project team, represented by the different highlighted areas accompanied by numbers on Figure 2.

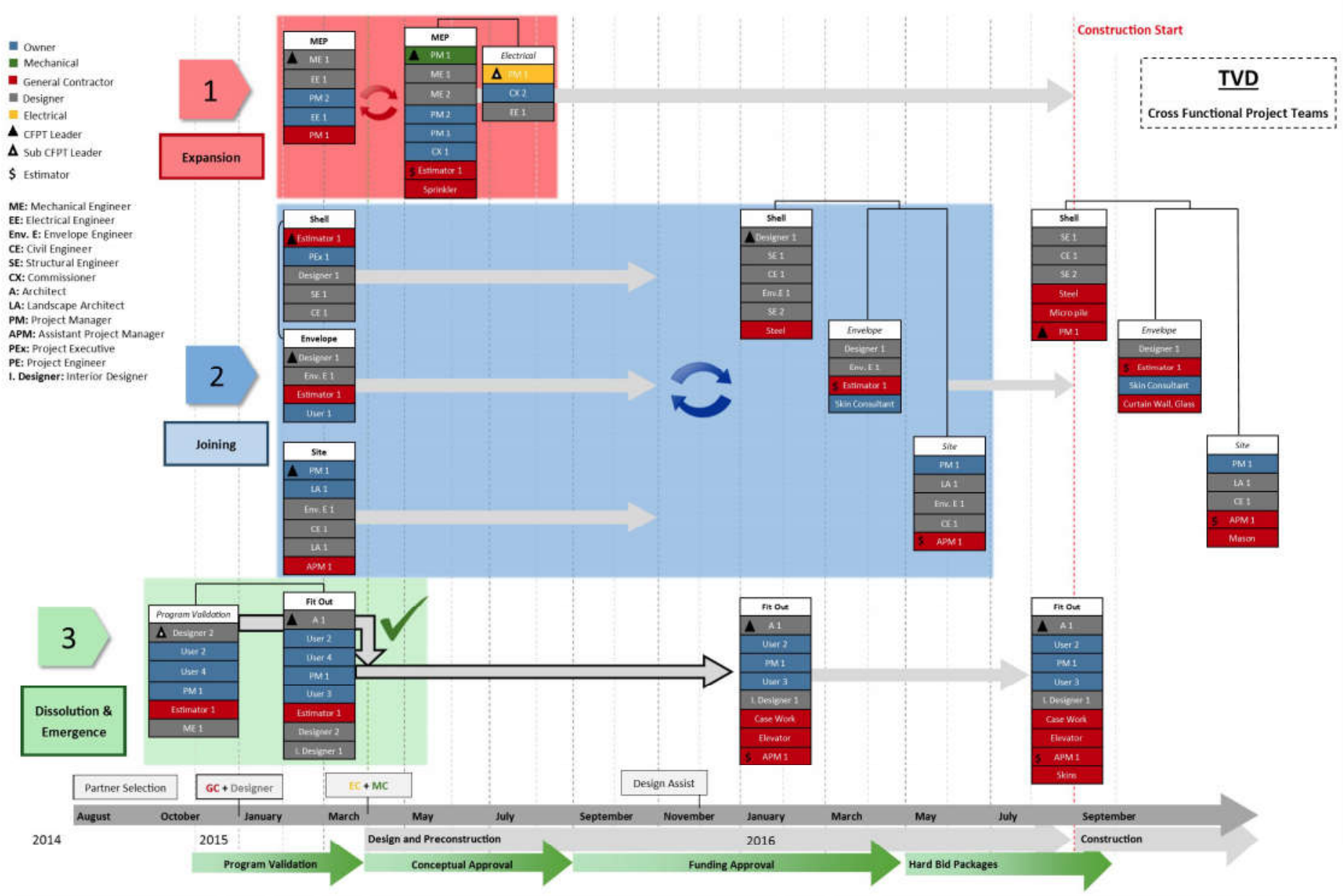

Figure 2: Cross-Functional Project Teams evolution through design phase - Types of changes

Type " 1 " in red refers to a change experienced due to the expansion of the CFPTs through the on-boarding of new project participants, in this case the Mechanical and 
Electrical contractors. The new CFPT combined the MEP CFPT and Electrical CFPT, as well as engaging the new Electrical and Mechanical contractor partners. The original logic for the two CFPTs was that they both needed to hold separate meetings focusing on specific system topics. However, as the systems work closely together, it is important to create the cross-functional communication as a single team to assure an appropriate flow of information. Eventually, the on-boarding of new project participants impacted the organization and the need for a more capable leader, bringing the builder's input and more scope specific expertise, which Figure 2 highlights.

Type "2" in blue relates to a change brought about by the project team when they realized a lack of interaction related to the Envelope and the Site. Originally, Shell and Envelope were gathered under one CFPT. However, Site was a separate CFPT with its own meetings and agenda. The project team realized that the Site CFPT due to the relatively small site area, required extensive collaboration with the building's Envelope design. Thus, the project team decided to gather the CFPTs under one main CFPT led by "designer 1." In this case, the team described this individual as more capable of leading such large CFPT, by showing extensive leadership skills and technical expertise. From then on the CFPT held meetings with all of the members in order to collaboratively develop the design and exchange information. In summer 2016, to prepare for construction, the leadership transferred to "project manager 1" from the GC because it is believed he is more able to bring field input and coordinate with subcontractors at this stage of the project.

Type " 3 " in green is the last type of change experienced during this case study. The Program Validation is a task CFPT that focused on area repartition and definition in order to allow the rest of the project team to begin design. This CFPT took place at the very earliest stage of the design phase, once completed, the specific team was dissolved and reemerged into the Fit-out CFPT with a revised make-up and principal activities that are based on the elements developed during the program validation. It appears that "designer 2" was brought on the project to focus on this specific program validation task; this explains why this person left the group after the completion of the task. When Program Validation merged into Fit-out, the senior "architect 1" from the Designer took over the leadership of the CFPT.

\section{DISCUSSION}

The $\mathrm{ABE}$ project team organized participants into different scope specific, TVDoriented, CFPTs that gathered individuals from different companies. The case study showed that the CFPTs focus on elements related to the main building systems of the project and their intersections. Additionally, each CFPT is expected to collaborate in order to reach the project goals and target cost set at the project outset. The three types of CFPT modifications observed were identified in different ways. Sometimes the team realized that their organization was not sufficient for a task or for coordination, which led to a reorganization or a transition of leadership. Other times, the team simply reviewed their organization in order to accommodate new firms joining the project team. Finally, one CFPT stopped when the objective was reached. These changes suggest that the team organization is organic and is based on the principles of flexible capacity and continuous improvement. However, these observations and specific changes might not occur on every IPD project. Variables, such as project type, size and goals, have a significant impact on team size, composition and evolution. This case study is limited to a medium-sized IPD project of $\$ 30$ million gathering five signatory members and approximately twenty fully 
involved participants during the design phase. Furthermore, this case study highlights the importance of the IPD contract related to how a specific role can be fulfilled by different people in order to best suit the project team needs at a given time. Members can be added to a specific CFPT instead of adding members from a different company without having to revisit the contract values of the companies involved. Additionally, the CFPT organization combined with the IPD contract allows the full potential of individuals to be realized to support CFPT needs. As seen in the case study, some members are removed or switched from one CFPT to another if they do not add value to the process in their original placement. The structure is flexible and allows the team to continuously evolve the CFPTs in parallel with the changing design processes to better use team member skills. These characteristics enhance the cross-functional organization of the team and allow for greater opportunity for collaboration and innovation.

\section{CONCLUSIONS}

The elements arising from this case study are beneficial to the lean community and more specifically the project team members that are unfamiliar with the concepts of IPD and CFPTs. In IPD, participants are divided in CFPTs to focus on a TVD approach. Each CFPT focuses on a specific scope depending on the project and building systems. The CFPTs are composed of participants from the different project firms that have the capacity to bring value to the design process. Using CFPTs establishes a specific group of people to work on a scope with a set of practices, TVD goal, information share and communication. On top of this, the CFPTs also need to apply the concept of cross-functional communication from one CFPT to another. IPD, being a relatively new contract form, is sometimes difficult to properly engage participants into the process. However, the flexibility of CFPTs in conjunction with an IPD contract allows evolution and flexibility in the team organization, providing greater opportunity for integration and development of cohesive groups to deliver project performance. The CFPTs evolve either by changing organization or by rotating members to better suit the project needs. Some participants interviewed during the case study highlighted their difficulties to see the need for IPD and the benefits of using early in the process. Those same participants later specified that by experiencing it and having all members working towards achieving a common goal the design process was more collaborative, allowing for better performance related to project goals. The use of CFPT seems more appropriate to IPD projects, but could be utilized on other type of project deliveries. The challenge implementing CFPTs in non-IPD contracts would lie in easily transition member roles between companies to fill a gap when there is a need because it would require a renegotiation of several contracts.

To expand this case study and obtain a broader picture of CFPTs organization in integrated construction projects a qualitative research will be pursued. Consisting of interviewing a set of IPD experts would allow for a confirmation of practices used during this case study and obtaining additional information concerning the type and evolutions of CFPTs on others projects experienced by the experts. Ideally, the most effective way to provide a full representation of organizational changes related to CFPTs would be to compare several case studies with regard to the overall projects performance. Each project would show a specific set of CFPTs organization at each project stage and evolution analysed against the final project performance to assess whether CFPT organization impacted performance and the recurring elements across case studies. 


\section{REFERENCES}

AGC (2009). "Consensus Documents." Associated General Contractors of America. AIA (2007). "Consensus Documents 300." American Institute of Architects.

Aime, F., Humphrey, S., Derue, D. S., and Paul, J. B. (2011). "The Riddle of Heterarchy: Power Transitions in Cross-Functional Teams." Academy of Management Journal, 57.

Cheng, R. (2015). "Integration at its Finest: Sucess in High-Performance Building Design and Project Delivery in the Federal Sector."

El-Asmar, M., Hanna, A. S., and Loh, W.-Y. (2013). "Quantifying Performance for the Integrated Project Delivery System as Compared to Established Delivery Systems." Journal of Construciton Engineering and Management, 139.

Henke, J. W., Krachenberg, A. R., and Lyons, T. F. (1993). "Perspective: Cross-Functional Teams: Good Concept, Poor Implementation!" Journal of Product Innovation Management, 10.

Hickethier, G. \& Tommelein, I.D. 2013, 'Social Network Analysis of Information Flow in an IPD-Project' In:, Formoso, C.T. \& Tzortzopoulos, P., 21th Annual Conference of the International Group for Lean Construction. Fortaleza, Brazil, 31-2 Aug 2013. pp 319-328

Konchar, M., and Sanvido, V. (1998). "Comparison of U.S Project Delivery Systems." Journal of Construciton Engineering and Management.

Krajewsky, L. J., and Ritsman, L. P. (2005). Operations Management: Processes and Value Chains., Upper Saddle River.

Leicht, R. M., Molenaar, K. R., Messner, J. I., Franz, B. W., and Esmaelli, B. (2015). "Maximizing Success in Integrated Projects: An Owner's Guide." Construction Industry Institute.

Ling, F. Y. Y., Chan, S. L., Chong, E., and Ee, L. P. (2004). "Predicting Performance of Design-Build and Design-Bid Build Projects." Journal of Construciton Engineering and Management.

Mossman, A. (2008). "What is Integrated Lean Project Delivery?".

Pishdad-Bozorgi, P., Moghaddam, E. H., and Karasulu, Y. "Advancing Target Price nd Target Value Design Process in IPD using BIM and Rish-Sharing Approaches." Proc., 49th Associated Schools of Construction Annual International Conference.

Qiu, T., Qualls, W., Bohlmann, J., and Rupp, D. E. (2009). "The Effect of Interactionnal Fairness on the Performance of Cross-Functional Product Development Teams: A Multilevel Mediated Model." Journal of Product Innovation Management, 26.

Seed, W. R. (2015). Transforming Design and Construction: A Framework for Change.

Sive, T., and Hays, M. (2009). "Integrated Project Delivery: Reality and Promise. A Strategist's Guide to Understanding and Marketing IPD." Society for Marketing Professional Services Foundation.

Thomsen, C. (2010). "Managing Integrated Project Delivery: Concepts and Contracts Strategies." CMAA.

UHS (2014). "Lean Project: Delivery Guide."

Zimina, D., Ballard, G., and Pasquire, C. (2012). "Target value design: using collaboration and a lead approach to reduce construction cost." Construction Management and Economics, 20(5). 